Research Article

\title{
Optimization Analysis Method of New Orthotropic Steel Deck Based on Backpropagation Neural Network-Simulated Annealing Algorithm
}

\author{
Xiuli Xu $\mathbb{D},{ }^{1}$ Kewei Shi $\mathbb{D}^{1},{ }^{1}$ Xuehong Li $\mathbb{D}^{1},{ }^{1}$ Zhijun Li $\mathbb{D}^{,},{ }^{1}$ Rengui Wang $\mathbb{D}^{2}$, and Yuwen Chen $\mathbb{D}^{1}$ \\ ${ }^{1}$ College of Civil Engineering, Nanjing Tech University, Nanjing 210009, China \\ ${ }^{2}$ CCCC Highway Consultants CO., Ltd., Beijing 100088, China
}

Correspondence should be addressed to Xiuli Xu; njxuxiuli@163.com

Received 26 June 2020; Revised 5 January 2021; Accepted 13 January 2021; Published 11 February 2021

Academic Editor: Emilio Bastidas-Arteaga

Copyright (C) 2021 Xiuli Xu et al. This is an open access article distributed under the Creative Commons Attribution License, which permits unrestricted use, distribution, and reproduction in any medium, provided the original work is properly cited.

\begin{abstract}
To study the effects of the fatigue performance due to the major design parameter of the orthotropic steel deck and to obtain a better design parameter, a construction parameter optimization method based on a backpropagation neural network (BPNN) and simulated annealing (SA) algorithm was proposed. First, the finite element (FE) model was established, and the numerical results were validated against available full-scale fatigue experimental data. Then, by calculating the influence surface of each fatigue detail, the most unfavorable loading position of each fatigue detail was obtained. After that, combined with the data from actual engineering applications, the weight coefficient of each fatigue detail was calculated by an analytic hierarchy process (AHP). Finally, to minimize the comprehensive stress amplitude, a BPNN and SA algorithm were used to optimize the construction parameters, and the optimization results for the conventional weight coefficients were compared with the construction parameters. It can be concluded that compared with the FE method through single-parameter optimization, the BPNN and SA method can synthetically optimize multiple parameters. In addition, compared with the common weighting coefficients, the weighting coefficients proposed in this paper can be better optimized for vulnerable parts. The optimized fatigue detail stress amplitude is minimized, and the optimization results are reliable. For these reasons, the parameter optimization method presented in this paper can be used for other similar applications.
\end{abstract}

\section{Introduction}

As a pivotal structure form of steel bridge decks, orthotropic steel decks possess features such as a low selfweight, high ultimate bearing capacity, and wide range of applications [1-3]. However, in the long-term service, fatigue cracking problems are present in many orthotropic steel bridge decks (OBDs). According to the statistics, fatigue almost accounts for $80 \%-90 \%$ of metallic failure [4-6]. Fatigue cracks occur for a variety of reasons, but there are three major reasons. First, the weld has quality defects of its own. Second, the single-side fillet weld between the longitudinal rib and deck plate is in an eccentric stress state when subjected to wheel loads, and the fatigue resistance is lower [7]. Third, the stiffness of the connections among the deck plate, longitudinal rib, and diaphragm are quite different, resulting in uncoordinated deformation. When combined deformation of out-of-plane bending and torsion occurs at the diaphragm due to the wheel load effects, a stress concentration can be generated at the rib-to-diaphragm details because of the restraint of the longitudinal rib on the diaphragm's lateral deformation, and the fatigue performance will be weakened $[8,9]$.

To address the problem outlined above, a new semiopened longitudinal rib orthotropic steel deck was designed (referred to as the new steel bridge deck in the following paper, Figure 1), and the 10 million cycles fatigue test on a full-scale partial model was completed. Each construction detail showed no sign of fatigue cracking, which indicated that the new steel bridge deck possessed relatively strong fatigue resistance performance [10]. However, the most unfavorable loading position of each fatigue detail was not considered in the fatigue test, and the stress of the rib-todeck weld joints was approximately $30 \%$ higher than that of 


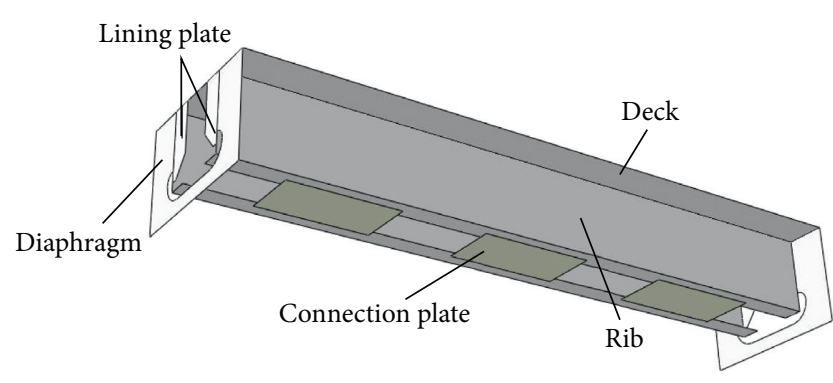

FIGURE 1: New orthotropic steel bridge deck structure.

conventional structures. Therefore, it is necessary to further analyze the influence of structural details and design parameters on the fatigue performance of a new steel bridge deck in order to obtain better structural parameters.

Scholars have carried out studies on the construction parameters of orthotropic steel decks. Kainuma et al. [11] performed full-scaled fatigue tests on orthotropic steel decks with different structure parameters, and the outcomes showed that raising the penetration rate had positive influences on preventing root cracking. Song et al. [12] considered the influence of geometric parameters on the fatigue performance through a parametric analysis model under wheel loads. Xia et al. [13] studied the effects of cutouts, the deck thickness, and other important parameters on the fatigue performance based on calibrated FE models. According to the results of the laboratory tests and parametric studies, suggestions for grid deck optimization design were given by Huang et al. [14]. De Corte [15] analyzed the influence of the rib height and rib inclination on the stress at the cutout. It was concluded that the load stresses decrease with both the rib height as well as the rib inclination. Oh et al. [16] studied the effect of the height, thickness, and shear area of cross-beam shapes of bulkhead plates and verified his results by tests. Then, they concluded that increasing the height, thickness, or shear area of the cross-beam reduced the maximum principal stress. The optimizations of OBDs were based on FE models and tests by single-factor analysis, which lacked comprehensive optimization of the structure parameters. With the development of computer technology, artificial intelligence is often used to accomplish the multiparameter optimization. Ahmadi et al. [17-19] studied the data forecasting based on the least square support vector machine (LSSVM), and acceptable results were obtained. After that, they used the genetic algorithm (GA) to optimize the results $[20,21]$. The artificial neural network (ANN) models and gene-expression programming (GEP) were adopted by Baghban and Ahmadi et al. [22-27] to estimate the hydrogen sulfide and carbon dioxide solubility in ionic liquids, and those models had a good performance of estimation. For structural optimization, Bagheri et al. [28] used a genetic optimization algorithm to evaluate the fuzzy reliability index. Meng et al. [29] solved the design problem of the wellhead 73platform based on reliability-based design and optimization (RBDO). Xin et al. [30] optimized the design parameters of the bridge based on the proposed multiscale optimization model. Zhuang et al. [31] established a partial FE model to optimize a steel box girder under vehicle loads. However, the weight coefficient was not considered in their work.

In this paper, a FE model was established for the new steel bridge deck based on tests and research. The FE model was verified through fatigue tests, and the influence surfaces of the major fatigue details were determined to locate the most unfavorable loading position. In addition, the parameter-optimizing method was established based on the combination of the BPNN and SA, and the weight coefficient of fatigue details was determined through the AHP according to the statistical data from practical engineering projects. At last, reasonable values of the major parameters were obtained. The flow chart is shown in Figure 2.

\section{New Orthotropic Steel Deck Structure}

The fatigue crack problem of regular orthotropic steel decks mainly occurs at the connection of the rib-to-deck and ribto-diaphragm. To optimize the fatigue performance of the fatigue details outlined above, the construction form of the steel bridge deck was redesigned, and a new orthotropic steel deck structure was proposed. The spacing of the longitudinal ribs was increased for the welding operations. At the bottom of longitudinal ribs, several connection plates were attached to guarantee the rigidity of the structure. The lining plates were provided at the diaphragm so that the integrity of the structure can be ensured. This new type of structure can also realize double-surface welding between the deck and longitudinal ribs, improve the welding quality between them and address the eccentric adaptive force problem of the welded seams of the single-edged angle [10]. Semiopened longitudinal ribs weaken the extent of the force concentration and improve the fatigue performance of the connection between the longitudinal ribs and diaphragms. The construction of the new steel bridge deck is shown in Figure 1.

The rib of the steel bridge deck in Figure 1 was $380 \mathrm{~mm}$ high, $400 \mathrm{~mm}$ wide, and $10 \mathrm{~mm}$ thick; the opening was $400 \mathrm{~mm}$ wide; the connection plate was $560 \mathrm{~mm}$ long, $280 \mathrm{~mm}$ wide, and $10 \mathrm{~mm}$ thick with a $430 \mathrm{~mm}$ longitudinal serial interval; the deck was $16 \mathrm{~mm}$ thick; the interval between intermediate diaphragms was $3.2 \mathrm{~m}$. The major fatigue details of the new steel bridge deck feature a diaphragm cutout (DC), rib-to-diaphragm joint (RDI), rib-to-deck joint (RD), deck-to-lining plate joint (DL), and rib-to-connection plate joint $(\mathrm{RC})$, which are shown in Figure 3.

\section{FE Simulation Test on Fatigue Performance of New Steel Bridge Deck}

The fatigue test results on the new steel bridge deck have been recorded in the literature [10]. This model measured $7000 \mathrm{~mm}$ long, and the lane width was set to $3500 \mathrm{~mm}$, including three diaphragms and four ribs, and two vertical ribs were set at the ends of the model considering the border effect. The wheel load position was $600 \mathrm{~mm}$ away from the diaphragm, and it was at the top of the rib-to-deck plate weld in the transverse direction. The 50-T actuator was selected as 


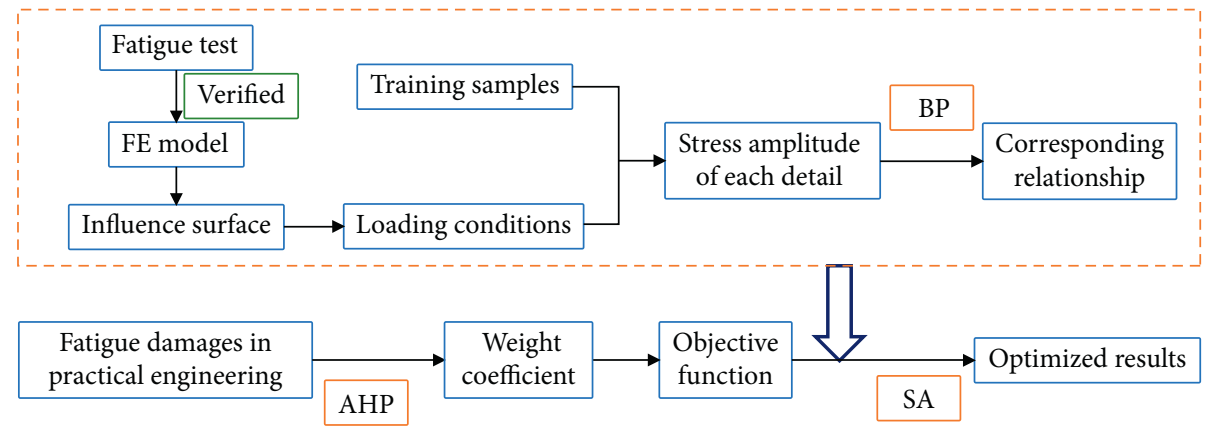

FIGURE 2: Flow chart of method in this paper.

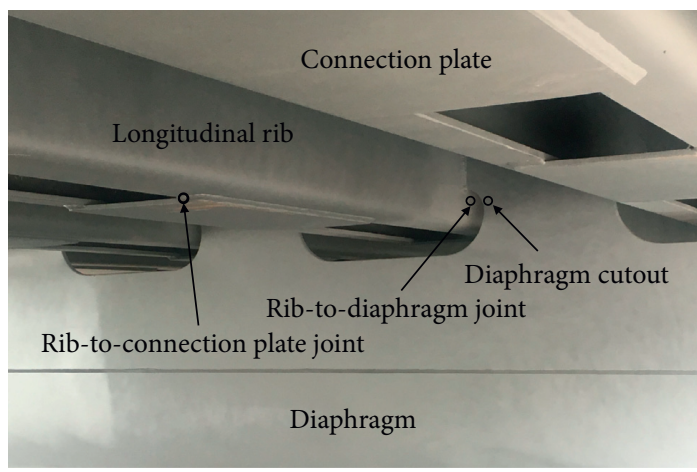

(a)

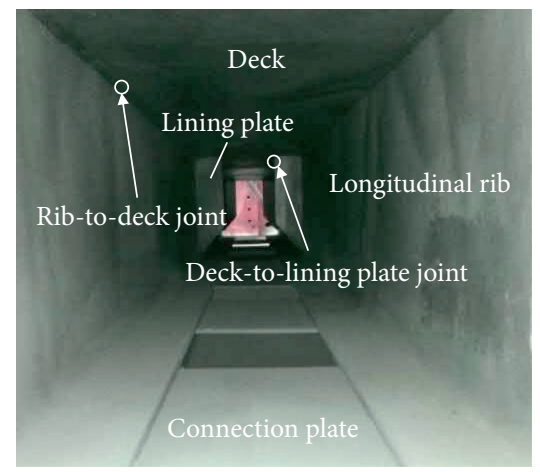

(b)

FIgUre 3: The location of each fatigue detail.

the loading device, and the load distribution beam was set under the actuator. The stress amplitude was set at $270 \mathrm{kN}$, and the number of load cycles for this fatigue test was 10 million. Considering the diffusion effect of the pavement layer, the loading area was $310 \mathrm{~mm} \times 710 \mathrm{~mm}$. Two 310 $\mathrm{mm} \times 710 \mathrm{~mm} \times 40 \mathrm{~mm}$ steel plates were installed at the bottom of the distribution beam to achieve uniform load transmission, and a $20 \mathrm{~mm}$ thick rubber mat was glued to the bottom of the steel plate. The constraint conditions of the experimental model adopted the method of bottom consolidation. The FE model is shown in Figure 4, the wheel load position is shown in Figure 5, and the test scene is shown in Figure 6.

To test the reliability of the FE modelling method, the outcomes of the models were verified. The model utilized a shell element simulation, and the sizes, thicknesses, construction details, loading methods, and border conditions were the same as those of the test model. In the test, the calculated values and measured values of the fatigue details were compared to verify the accuracy of the FE calculation. The FE calculated values and measured values of DC, RDI, and DL are shown in Figure 7.

Figure 7 shows the changing trends of both the calculated values and measured values of the measuring points of DC, RDI, and RD all showed linear changes. The calculated values of RDI and RD were slightly higher than the measured values, while the outcomes of DC showed the opposite phenomenon; the calculated values were slightly lower than

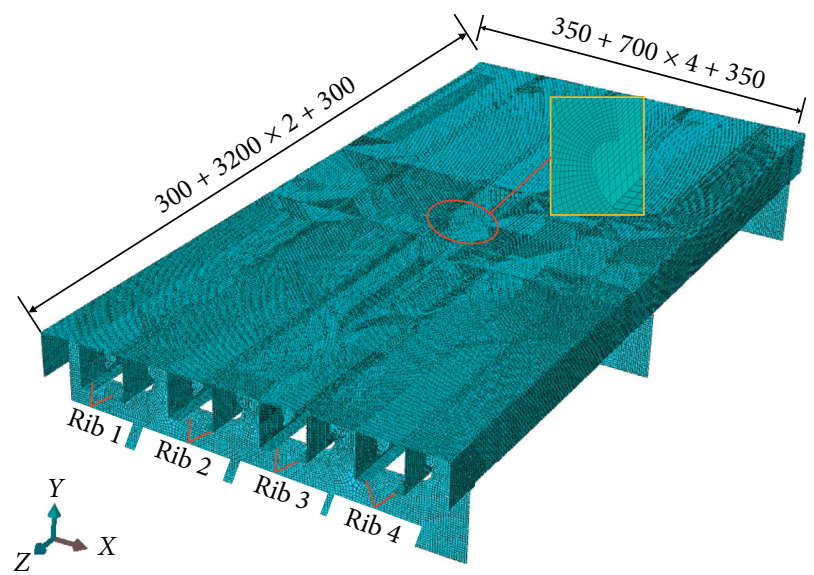

FIgURe 4: FE model of test.

the measured values. The primary reason for this phenomenon is that, during the loading process, the loading equipment tilted slightly toward the longitudinal direction, producing a small horizontal force; in the meantime, the force in the vertical direction was relatively lower compared to the FE load, and the measured values of RDI and RD, therefore, seemed to be low. This horizontal force caused large out-of-plane distortions of the intermediate diaphragms, while the out-of-plane distortion had a remarkable influence on the opening of the diaphragms. Consequently, 


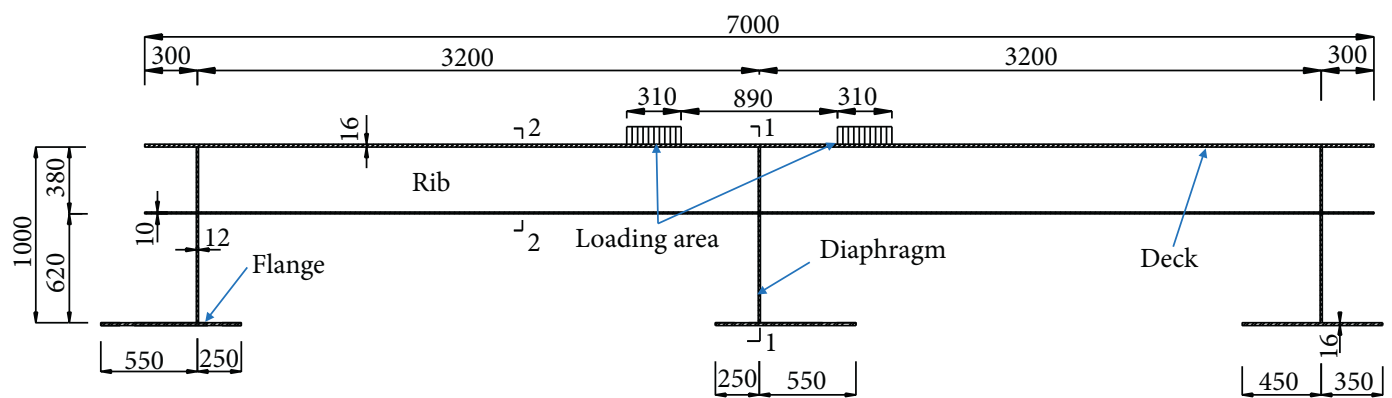

(a)

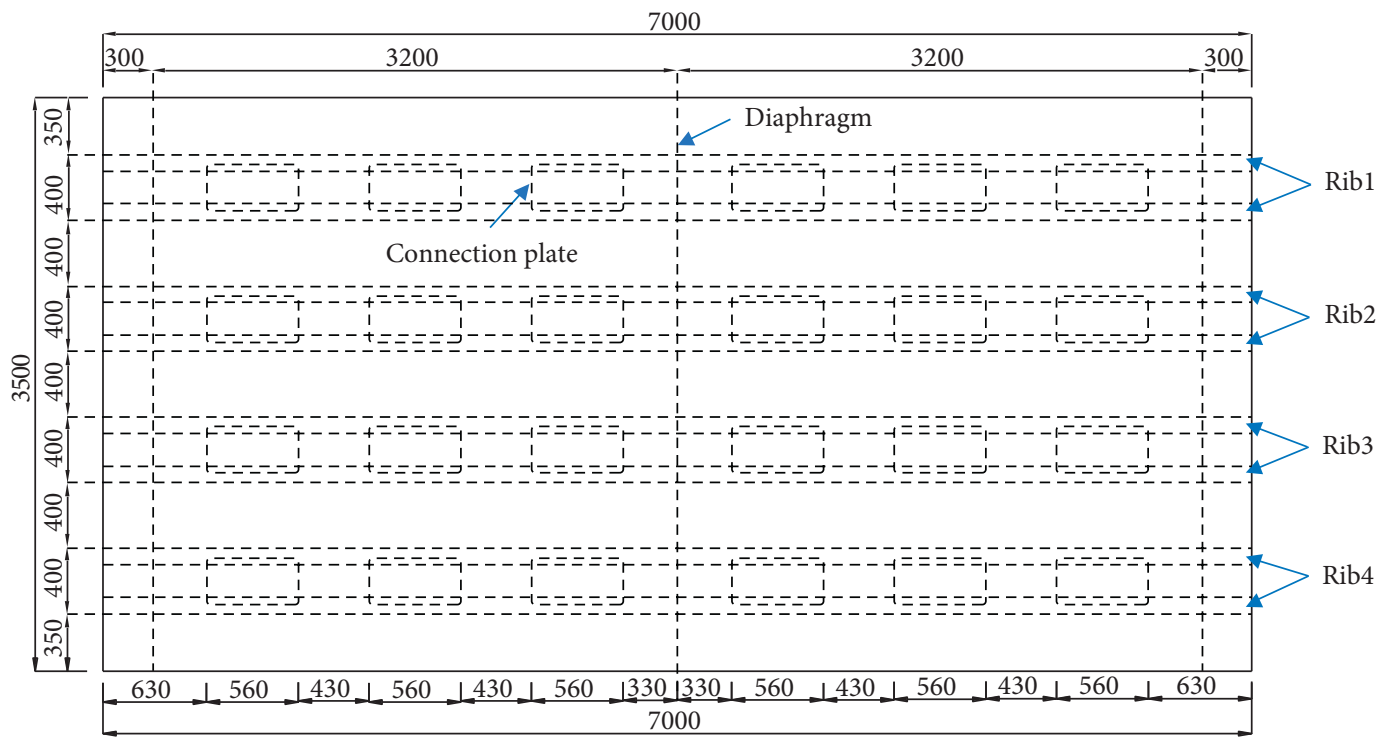

(b)

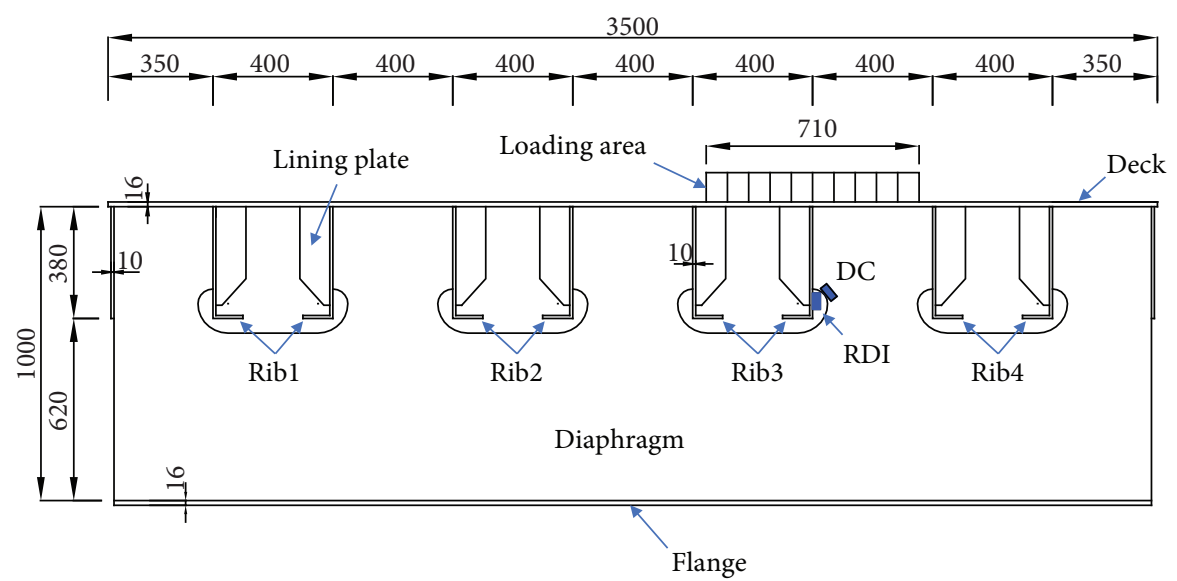

(c)

FIgURE 5: Continued. 


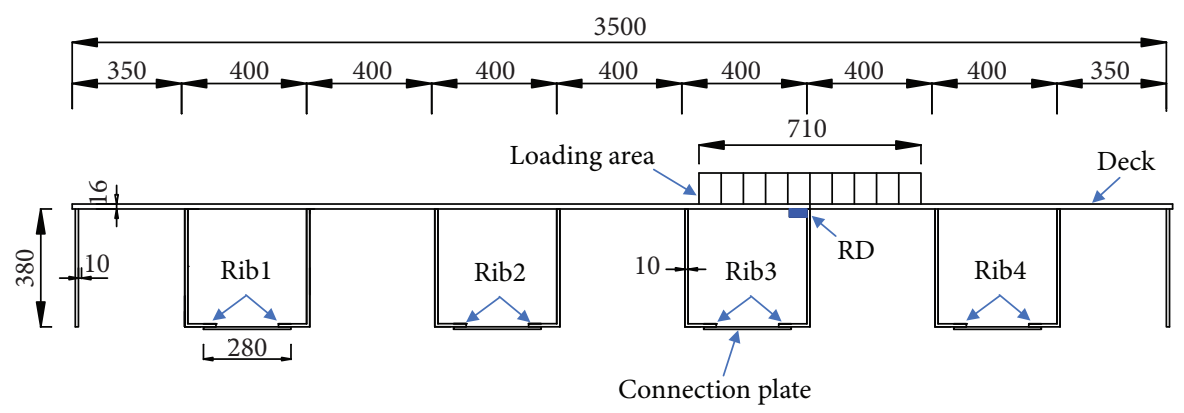

(d)

Figure 5: Wheel load position of fatigue test (unit: mm). (a) Elevations of model. (b) Upward view of model. (c) 1-1 Sectional view. (d) 2-2 Sectional view.

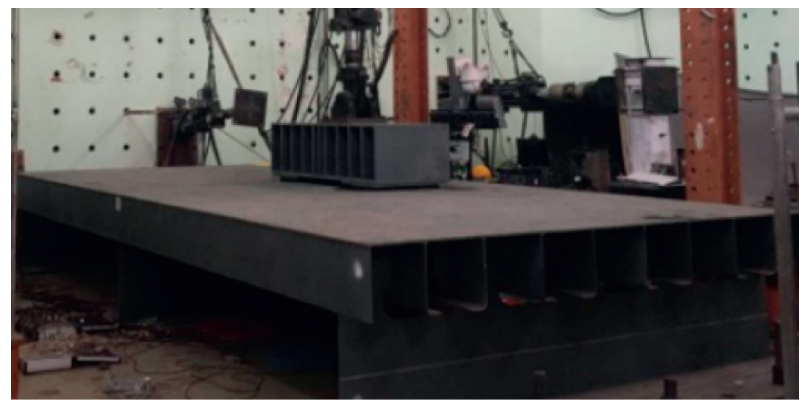

FiguRE 6: Test scene of new steel bridge deck.

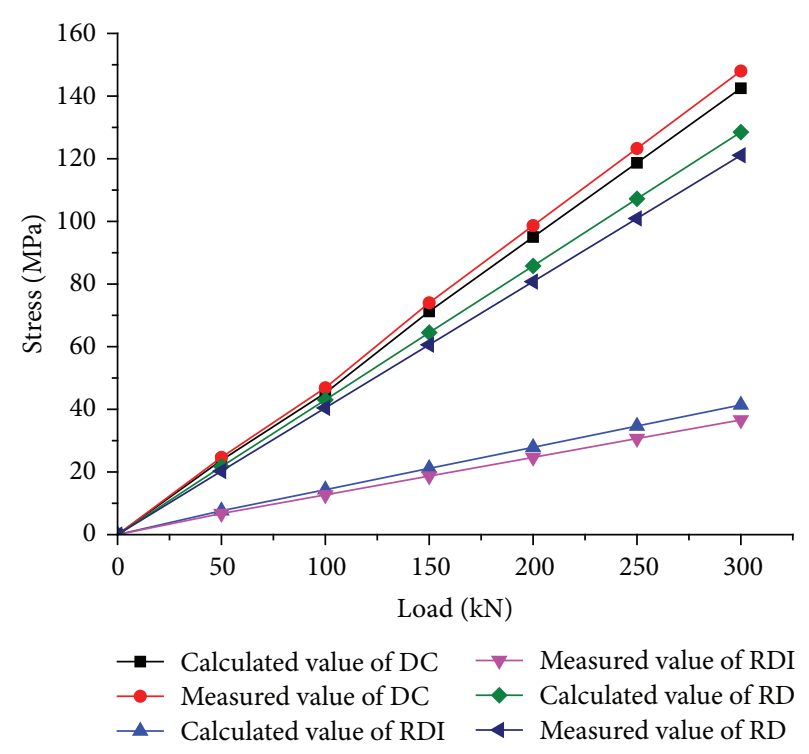

FIGURE 7: Measured and calculated values of stress.

the measured values of DC were relatively higher than the calculated values.

Overall, the measured values of the static load of the test model match the theoretical values of the FE model, and the patterns are consistent, which indicate that the FE model can effectively analyze the actual loading condition of the test model and that the FE model we built can be applied to structural performance analysis applications.

\section{Ensuring the Most Unfavorable Loading Position and Loading Condition}

The stress on the key details of the orthotropic steel deck is extremely sensitive to the wheel effect, and it is vitally important to locate the most unfavorable loading position of each fatigue detail [32-34]. Therefore, targeting each fatigue detail, the stress history of the wheel loading effect in different areas was established to create the influence surface and ensure the most unfavorable position of each fatigue detail.

4.1. Load Condition. The vehicle model of fatigue load III from the Chinese Specification for the Design of Highway Steel Bridges was selected to perform the calculation (which is shown as Figure 8), and the axle load was set to $120 \mathrm{kN}$. The wheel load area was set to $0.6 \mathrm{~m} \times 0.2 \mathrm{~m}$.

4.2. FE Model. To analyze the stress response of the new steel bridge deck under standard fatigue wheel load, a 3-D FE shell model was established that measured $25.6 \mathrm{~m}$ in the longitudinal direction, including 10 diaphragms and measured $8 \mathrm{~m}$ in the transverse direction, including 10 longitudinal ribs. The elastic modulus was set to $206 \mathrm{GPa}$, Poisson's ratio was set to 0.3 , and the type of mesh was S4. For the concentrated regions, the two sections that were within the range measured $6.4 \mathrm{~m}$ forward and back toward the deck were specialized into units, and the total model units added up to 813,457 , with regard to 810,901 joints. The border conditions were set as follows: the diaphragms' translational and rotational degrees of freedom were restricted in the $X, \mathrm{Y}$, and $Z$ directions; the translational degrees of freedom of the ends of the ribs' beam and deck were restricted in three directions, as shown in Figure 9.

4.3. Ensuring the Most Unfavorable Loading Position. The center of the standard fatigue vehicle wheel axle took the centerline of the 6th and 7th ribs (i.e., U6 and U7) as the initial position (shown as Figure 10), and the 6th longitudinal rib was the concerned position.

Considering the symmetry of the wheel load, 11 conditions were considered in the transverse direction, and 37 


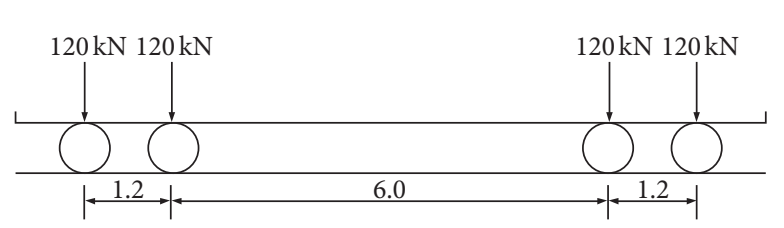

(a)

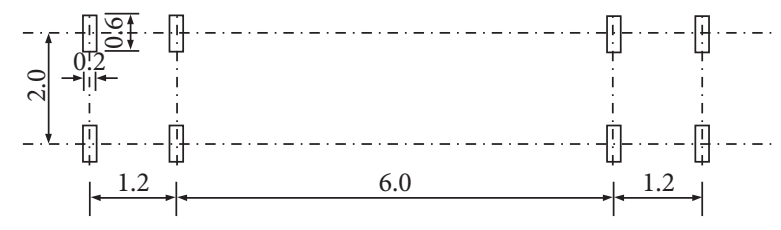

(b)

Figure 8: Fatigue load model (unit: m).

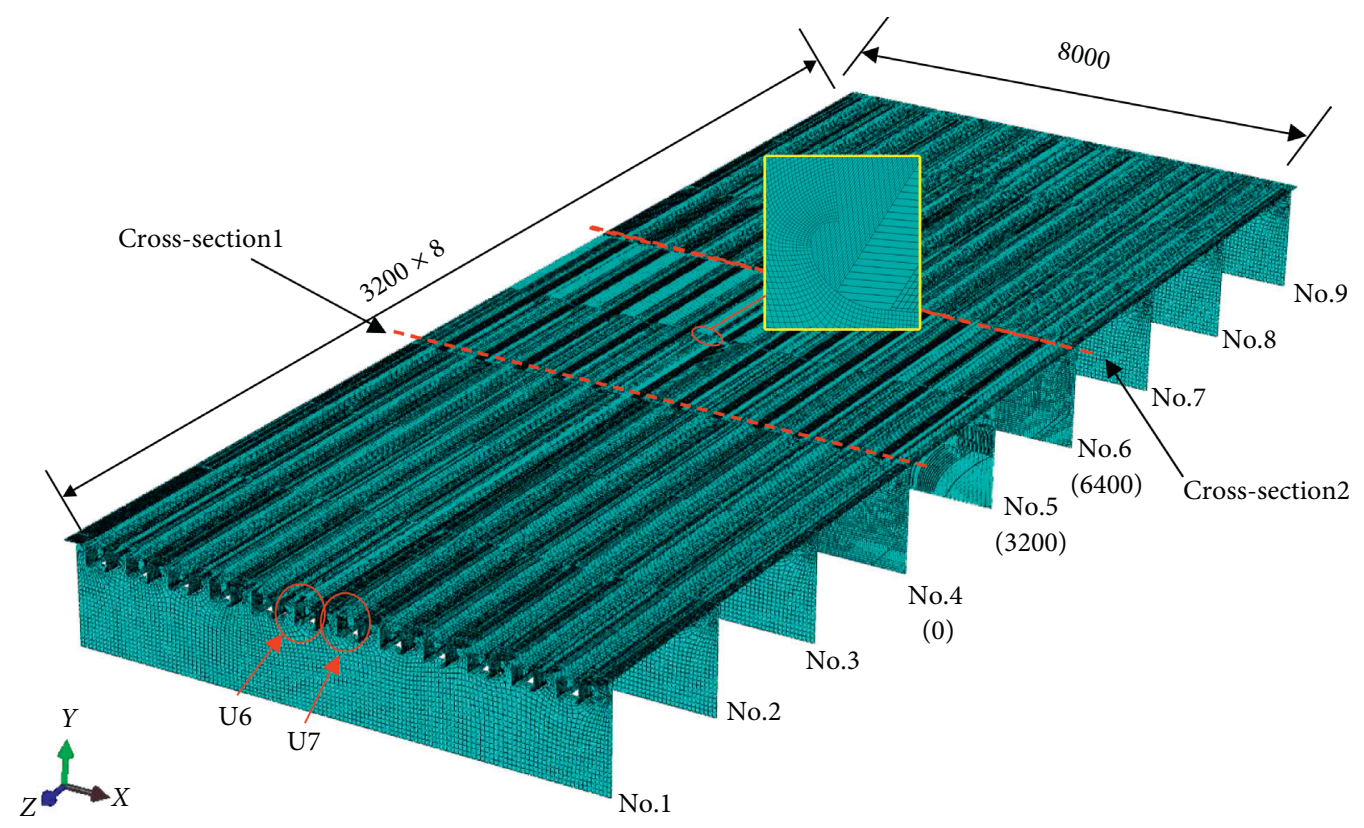

FIgURE 9: FE model of orthotropic steel deck (unit: $\mathrm{mm}$ ).

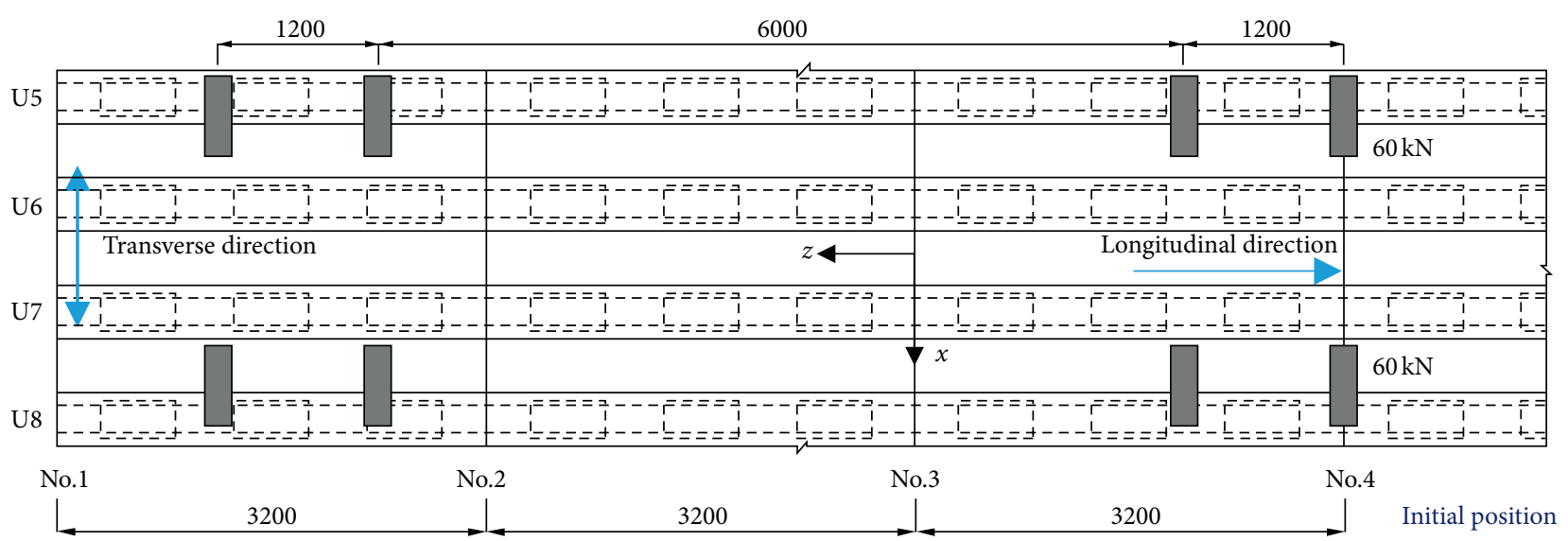

FIgURE 10: Wheel load moving direction (unit: $\mathrm{mm}$ ).

conditions were considered in the longitudinal direction. Based on the statistics of the outcomes of the FE calculation, the influence surface of each fatigue detail was established, which is shown in Figure 11.

The highest stress response position of RD was equal to the wheel loading effect position, and it changed following the changing trend of the wheel loading position. We could thus ascertain the most unfavorable position through the longitudinal and transverse stress change curves under the wheel loading effect, as shown in Figure 12.

From Figures 11 and 12, we can tell that the stress changing pattern of DC and RDI were basically the same. Specifically, the most unfavorable loading positions were both at a transverse location of $400 \mathrm{~mm}$ and a longitudinal location of $3800 \mathrm{~mm}$ on the bridge, which were above the 6 th longitudinal ribs in the transverse direction and $600 \mathrm{~mm}$ in 


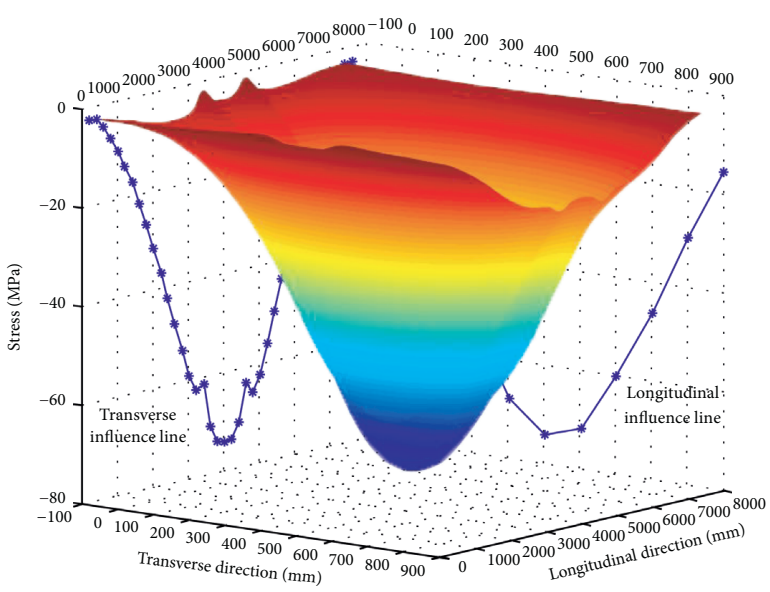

(a)

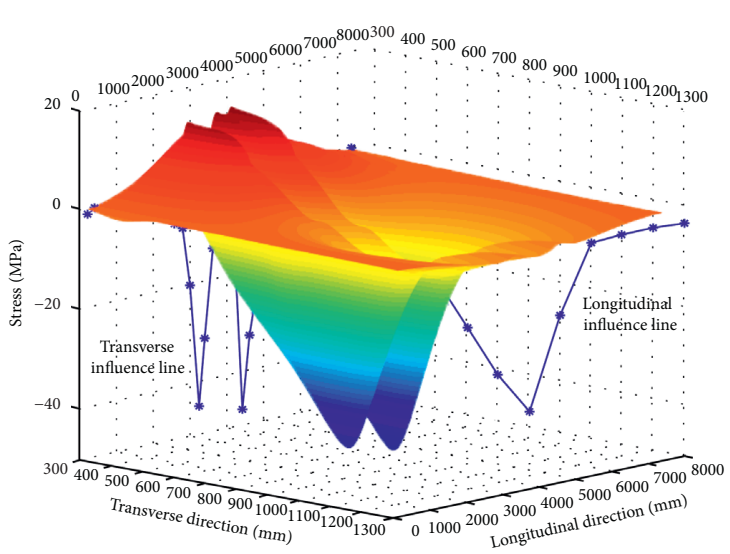

(c)

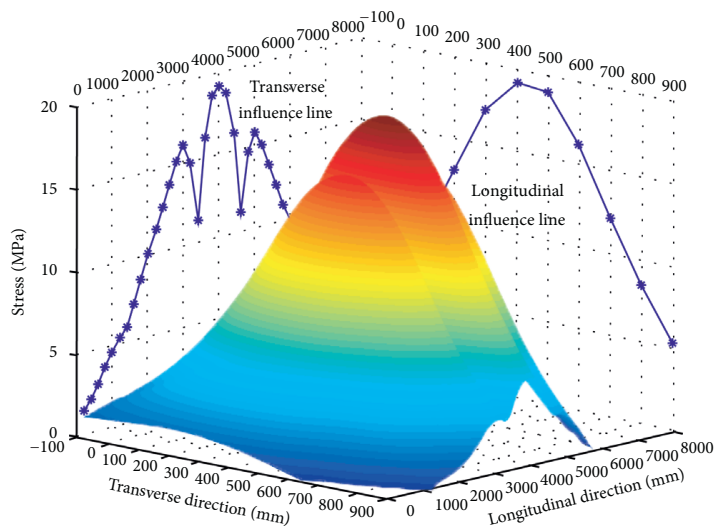

(b)

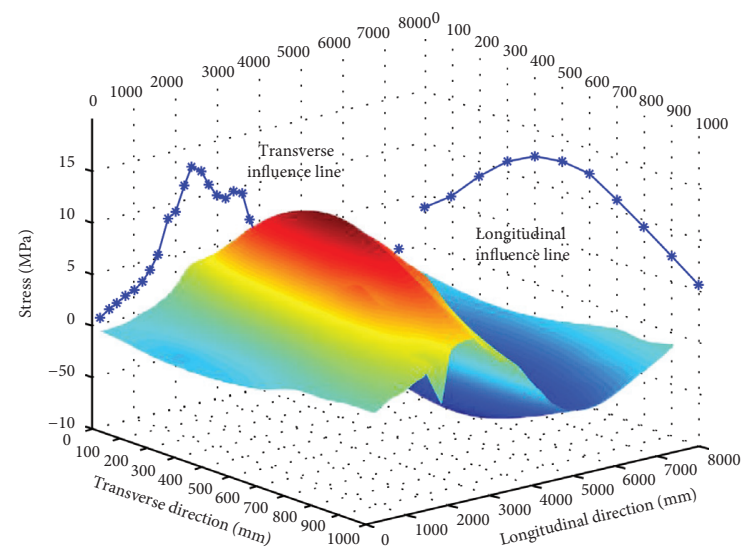

(d)

Figure 11: Fatigue detail influence surface. (a) DC. (b) RDI. (c) DL. (d) RC.

longitudinal direction from the 5th diaphragm. The values of the stress on DC and RDI fluctuated, and the primary cause was that the wheel load was directly loaded at the position of the lining plate.

The most unfavorable loading position of $\mathrm{RD}$ was at a transverse location of $400 \mathrm{~mm}$ and a longitudinal location of $3600 \mathrm{~mm}$ on the bridge, which was above the web of the 6 th longitudinal rib in transverse direction and $400 \mathrm{~mm}$ from the 5th diaphragm in the longitudinal direction.

The most unfavorable loading position of DL was at a transverse location of $800 \mathrm{~mm}$ and a longitudinal location of $3200 \mathrm{~mm}$ and $4400 \mathrm{~mm}$ on the bridge, which was $300 \mathrm{~mm}$ from the lining plate in the transverse direction and above the lining plate in the longitudinal direction. Besides, the wheel loading effect area of DL was relatively small.

The most unfavorable position of RC was at a longitudinal location of $2400 \mathrm{~mm}$ and a transverse location of $500 \mathrm{~mm}$ on the bridge, which was above the connection plate on which we concentrated in the transverse direction and $800 \mathrm{~mm}$ from the 5 th diaphragm in the longitudinal direction. Moreover, due to the wheel loading effect, the force values changed from tensile stress to compressive stress. According to the calculation, the values of the stress amplitude of RC were approximately $20 \mathrm{MPa}$, which was much lower than its fatigue level of 80 (Eurocode3 specifications). To simplify the calculation, we did not consider the influences of RC itself.

The most unfavorable position and loading condition of each fatigue detail is shown in Figure 13. Because the most unfavorable position of RD was very similar to those of DC and RDI, the stress difference between them was approximately $2 \%$. During the following loading condition calculation, the most unfavorable loading position of RD was considered as loading condition 1 .

\section{Optimizing the Parameter of the New Orthotropic Steel Bridge Deck Based on BP- SA-AHP Method}

The fatigue performance and fatigue life of the fatigue details are related to the stress amplitude under the wheel load $[35,36]$. Considering the axle load of the wheel load and pavement layer, the loading amplitude for a single wheel load was considered to be $60 \mathrm{kN}$, and the wheel load area was $710 \mathrm{~mm} \times 310 \mathrm{~mm}$. According to the settled loading conditions above, the stress amplitude of each fatigue test was calculated based on different construction parameters. The 


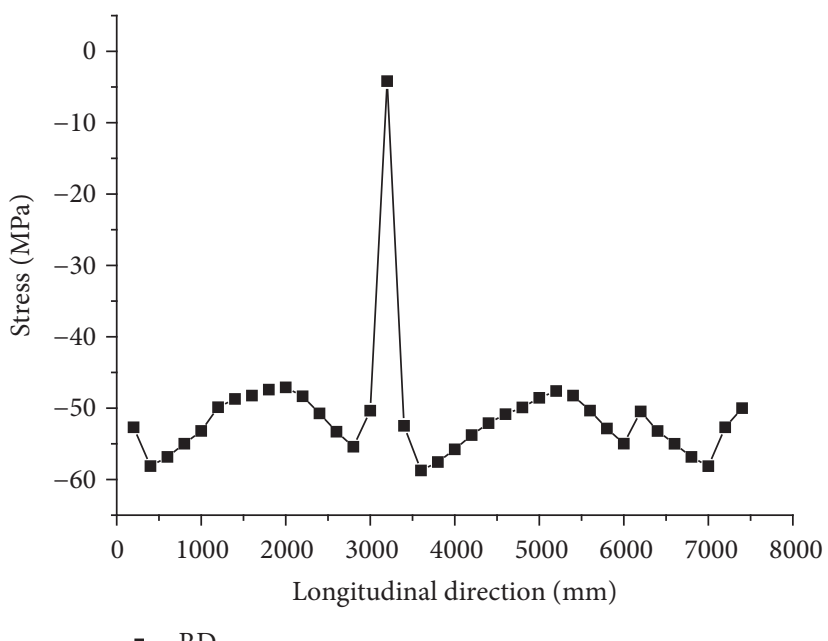

(a)

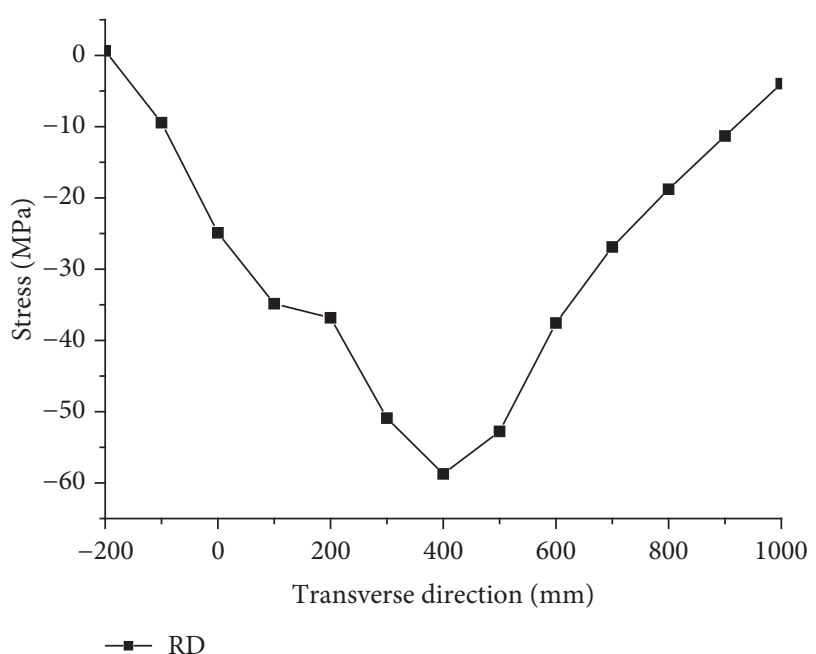

(b)

FIgURE 12: Longitudinal and transverse stress curve of RD.
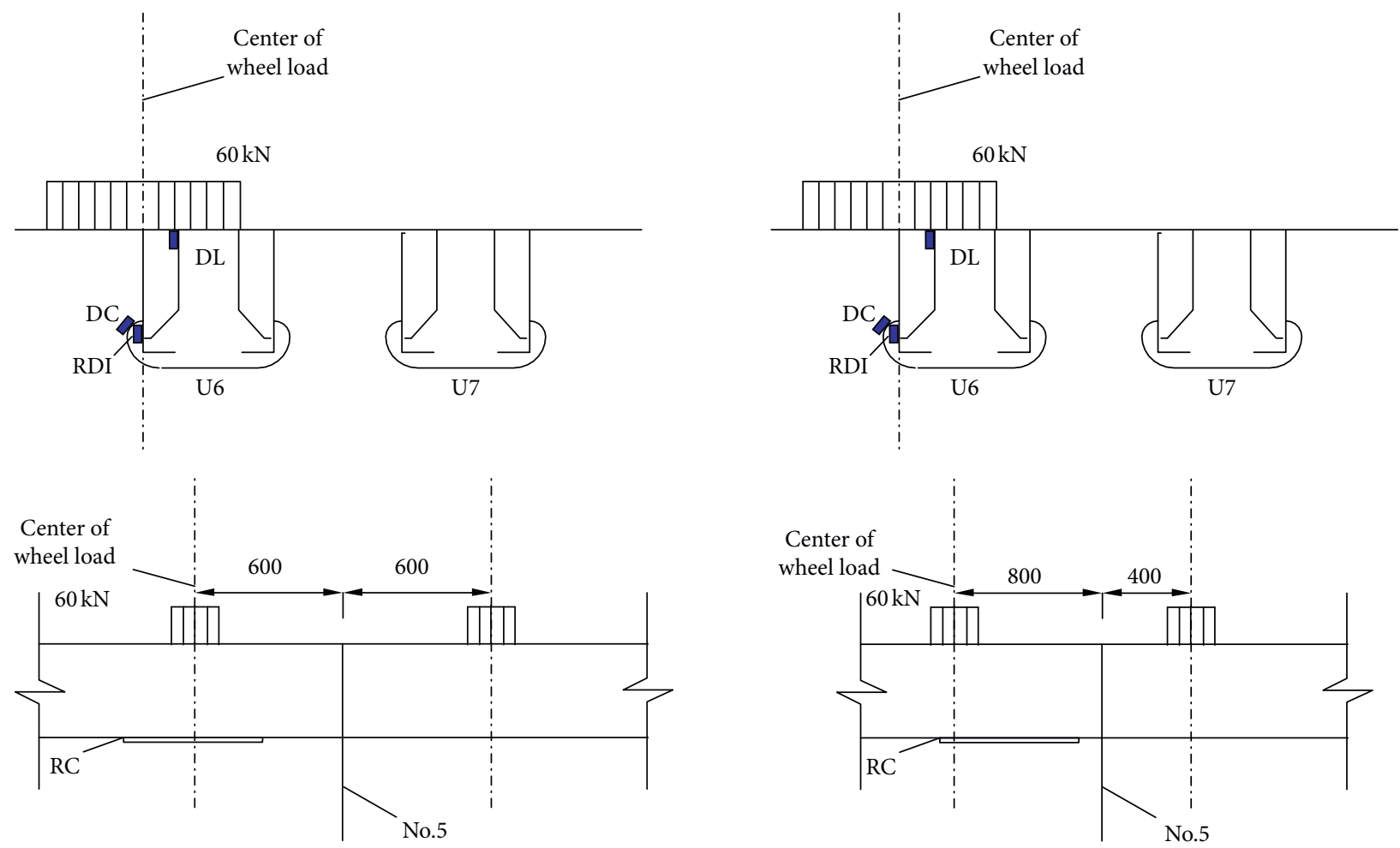

(a)

(b)

Figure 13: Continued. 

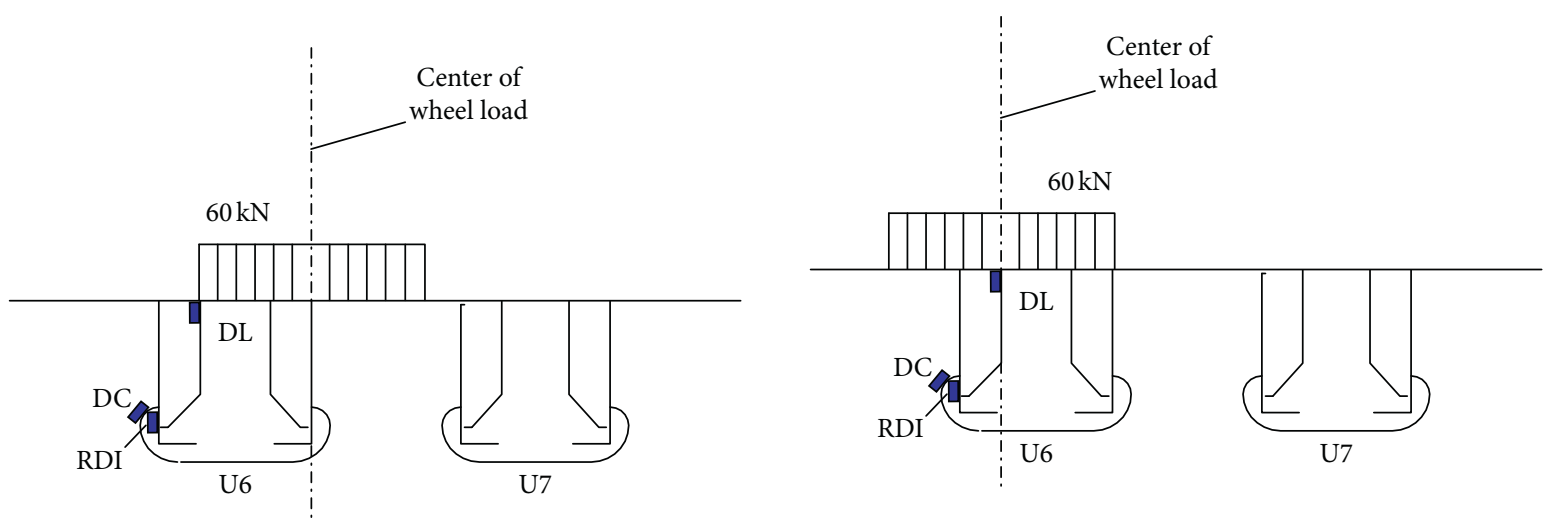

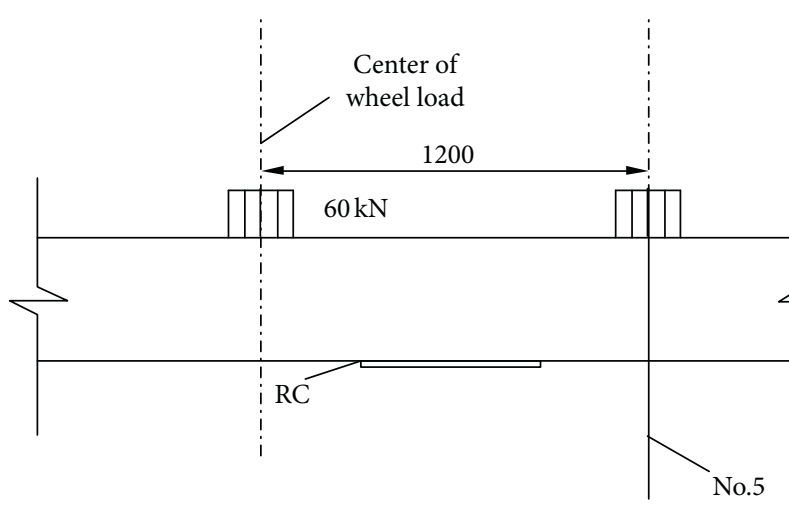

(c)

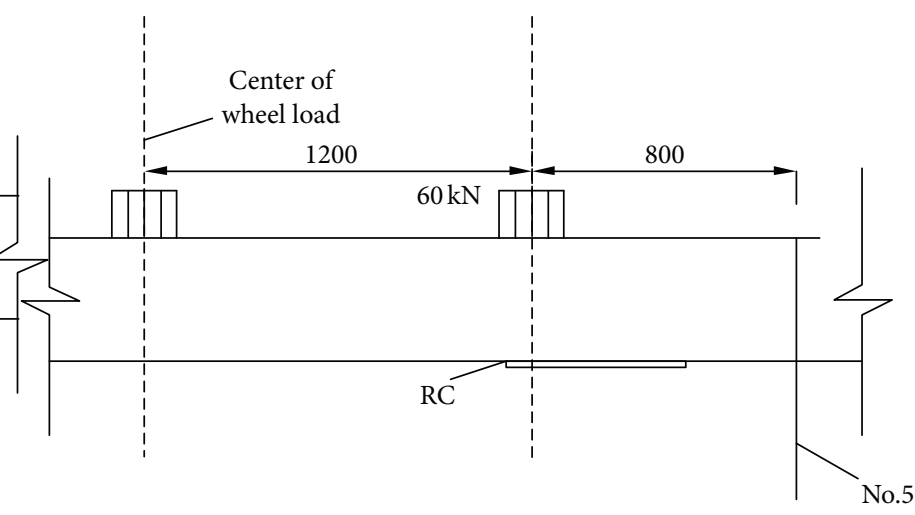

(d)

FIgURE 13: The most unfavorable loading position of each fatigue detail. (a) DC and RDI (condition 1). (b) RD. (c) DL (condition 2). (d) RC.

corresponding relationship between stress amplitudes of the fatigue details and construction parameters was established based on the BPNN algorithm, and the values were selected for the weight coefficients of the fatigue details through AHP. After optimizing the outcomes by SA, the optimized construction parameters of the new orthotropic steel bridge deck were obtained. The workflow is shown in Figure 14.

\subsection{Ensuring the Training Samples and the Test Samples.} It is reported [37-40] that when the thickness is too large, the welding penetration rate of the orthotropic steel bridge deck will be reduced, and the welding quality will decline. Moreover, the increase of thickness will lead to excessive welding residual stress. These factors will weaken the fatigue life of OBDs. When the thickness is too small, it will lead to excessive deflection. Therefore, according to the Eurocode3 specifications and stiffness requirements, 5 dimensions were selected as the optimized range, as is shown in Table 1 . Considering the samples were distributed evenly, we added the samples through the L25 Taguchi orthogonal array method [41], as shown in Table 2, among which five samples were chosen as the test samples, as shown in Table 3. The total number of samples was $85+25$, featuring 105 sets of training samples and 5 sets of test samples.
In the tables above, $h$ stands for the height of the ribs, $t_{d}$ stands for the thickness of the deck, $t_{h}$ stands for the thickness of the diaphragm and lining plate, $t_{r}$ stands for the thickness of the ribs, and $t_{l}$ stands for the thickness of the connection plate. The parameters above functioned as design variations, and the stress amplitudes of fatigue details were objective functions. The five construction parameters were used as input variations, and the stress amplitudes of five fatigue details were treated as output layers of the BPNN. After repetitive training on the BPNN through MATLAB software, the corresponding relationship between each construction parameter and the stress amplitude of each fatigue detail was obtained [22-26,31]. The prediction ability of the BPNN was evaluated by comparing with the (radial basis function neural network) RBFNN $[23,25]$ and SVM [17-19].

5.2. Predicted Outcomes. We could obtain the predicted values of the stress amplitude of each fatigue detail according to the test samples in training Table 3. The calculated and predicted values of three models are shown in Figure 15. Performance of proposed models can be measured by using the mean square errors (MSEs), mean relative errors (MREs), and standard deviations (STD) [24-27], which are 


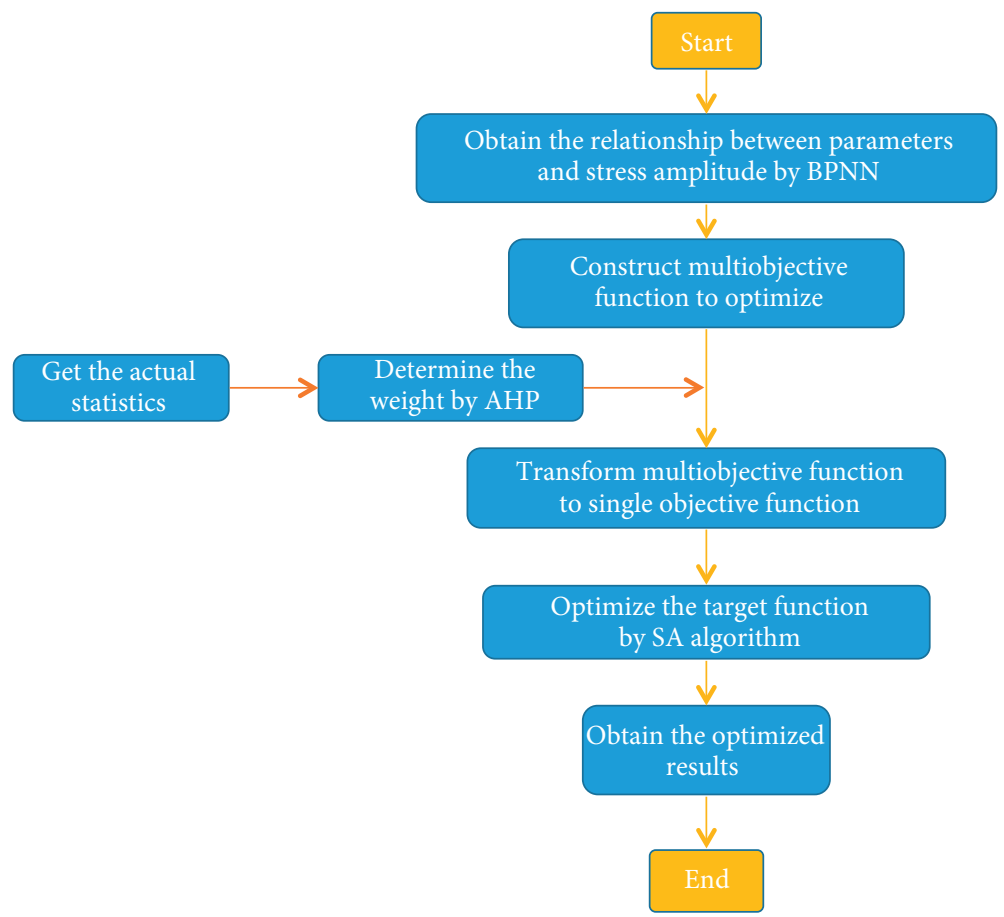

FIGURE 14: Workflow of BP-SA-AHP method.

TABLE 1: Training samples of single factor analysis (unit: $\mathrm{mm}$ ).

\begin{tabular}{lcccc}
\hline$h$ & $t_{d}$ & $t_{h}$ & $t_{r}$ & $t_{l}$ \\
\hline $340-420$ & $14-18$ & 12 & 10 & 10 \\
$340-420$ & 16 & $10-14$ & 10 & 10 \\
$340-420$ & 16 & 12 & $8-12$ & 10 \\
$340-420$ & 16 & 12 & 10 & $8-12$ \\
\hline
\end{tabular}

shown in Table 4. Formulas of the MSEs, MREs, and STD are shown in the following equations:

$$
\begin{aligned}
& \text { MSE }=\frac{1}{N} \sum_{i=1}^{N}\left(\alpha_{\text {pre }}-\alpha_{\text {cal }}\right)^{2}, \\
& \operatorname{MRE}=\frac{1}{N} \sum_{i=1}^{N} \frac{\left|\alpha_{\text {pre }}-\alpha_{\text {cal }}\right|}{\alpha_{\text {pre }}}, \\
& \operatorname{STD}=\left(\frac{1}{N-1} \sum_{i=1}^{N}(\text { error }-\overline{\text { error }})^{2}\right)^{0.5} .
\end{aligned}
$$

It can be seen from Figure 15 and Table 4, the accuracy of BPNN, RBFNN, and SVM can reach more than 90\%, which meant that three models were able to reflect the relationship between the design parameters and the stress amplitude. Compared with SVM, for multiobjective and multiparameter prediction, ANN had a better estimation. Compared with the two ANN models, the MSE, MRE, and STD of BPNN were smaller, which meant that BPNN had higher

\begin{tabular}{|c|c|c|c|c|}
\hline$h$ & $t_{d}$ & $t_{h}$ & $t_{r}$ & $t_{l}$ \\
\hline \multirow{5}{*}{340} & 14 & 14 & 11 & 10 \\
\hline & 15 & 10 & 12 & 11 \\
\hline & 16 & 11 & 8 & 12 \\
\hline & 17 & 12 & 9 & 8 \\
\hline & 18 & 13 & 10 & 9 \\
\hline \multirow{5}{*}{360} & 14 & 13 & 9 & 12 \\
\hline & 15 & 14 & 10 & 8 \\
\hline & 16 & 10 & 11 & 9 \\
\hline & 17 & 11 & 12 & 10 \\
\hline & 18 & 12 & 8 & 11 \\
\hline \multirow{5}{*}{380} & 14 & 12 & 12 & 9 \\
\hline & 15 & 13 & 8 & 10 \\
\hline & 16 & 14 & 9 & 11 \\
\hline & 17 & 10 & 10 & 12 \\
\hline & 18 & 11 & 11 & 8 \\
\hline \multirow{5}{*}{400} & 14 & 11 & 10 & 11 \\
\hline & 15 & 12 & 11 & 12 \\
\hline & 16 & 13 & 12 & 8 \\
\hline & 17 & 14 & 8 & 9 \\
\hline & 18 & 10 & 9 & 10 \\
\hline \multirow{5}{*}{420} & 14 & 10 & 8 & 8 \\
\hline & 15 & 11 & 9 & 9 \\
\hline & 16 & 12 & 10 & 10 \\
\hline & 17 & 13 & 11 & 11 \\
\hline & 18 & 14 & 12 & 12 \\
\hline
\end{tabular}
accuracy. In the process of prediction operation, the
TABle 2: Samples of orthogonal array method (unit: $\mathrm{mm}$ ).

computing time of BPNN was $1.78 \mathrm{~s}$, and the computing time of RBFNN was $1.45 \mathrm{~s}$, which showed that RBFNN had a better efficiency. 
Table 3: Test samples (unit: mm).

\begin{tabular}{lccccc}
\hline Test samples & $H$ & $t_{d}$ & $t_{h}$ & $t_{r}$ & \\
\hline 1 & 340 & 18 & 13 & 10 & 12 \\
2 & 360 & 17 & 11 & 9 & 10 \\
3 & 380 & 16 & 14 & 11 & 11 \\
4 & 400 & 15 & 10 & 8 & 12 \\
5 & 420 & 14 & 12 & 8 \\
\hline
\end{tabular}
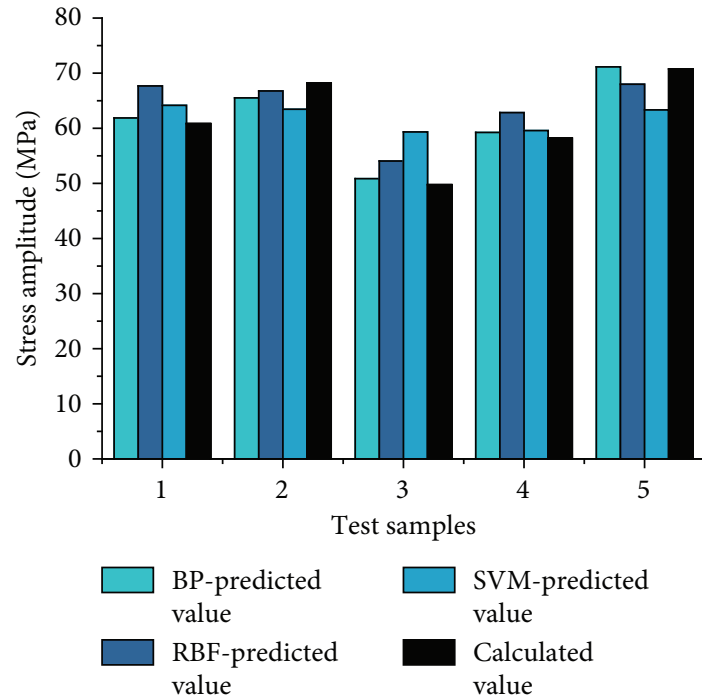

(a)
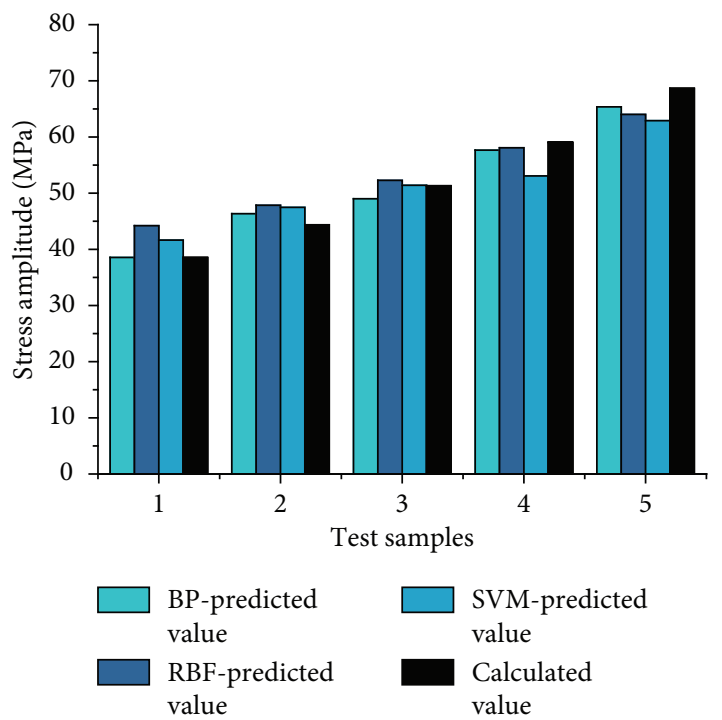

(c)
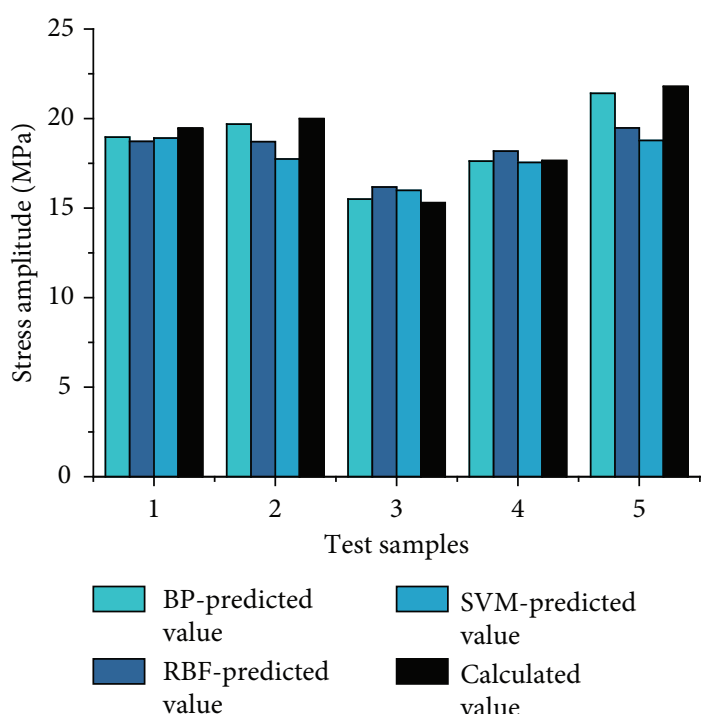

(b)
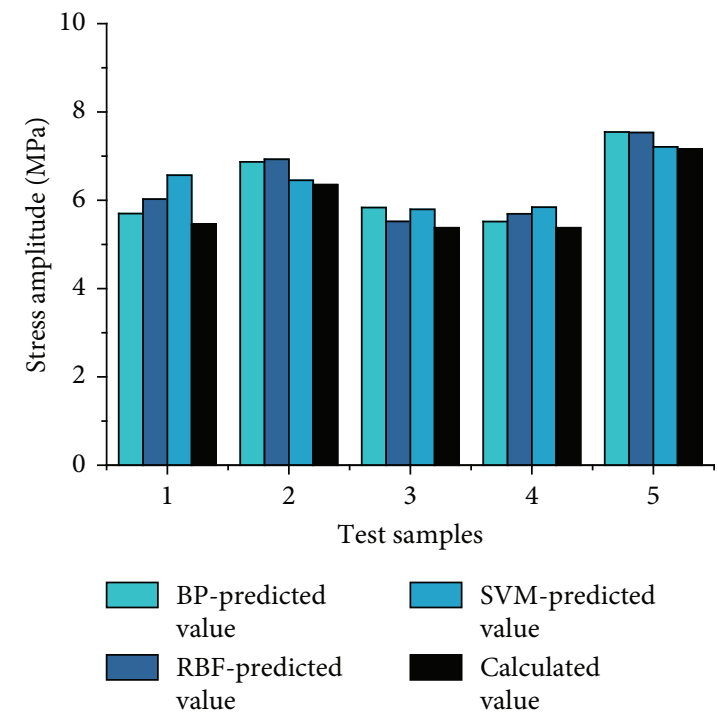

(d)

FIGURE 15: Continued. 


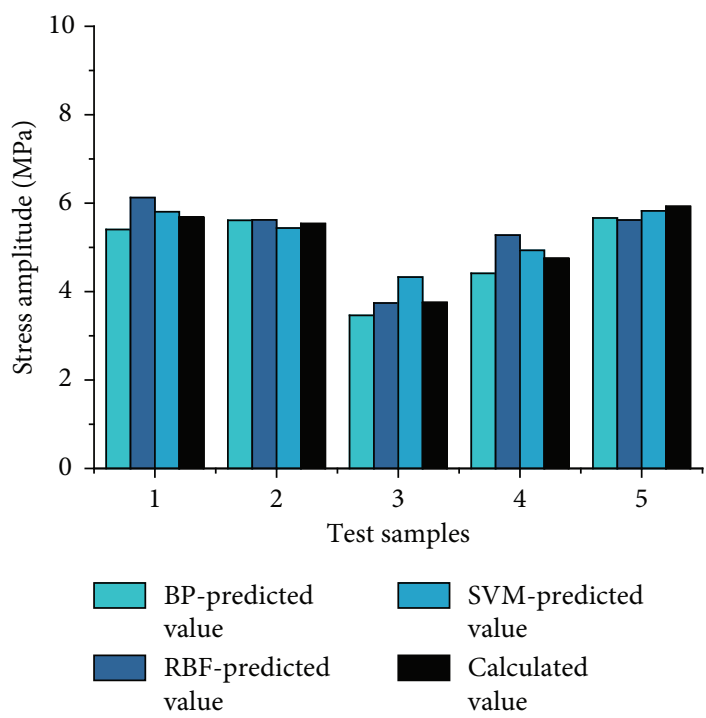

(e)

Figure 15: The outcomes of BPNN, RBFNN, and SVM. (a) DC. (b) RDI. (c) RD. (d) DL. (e) RC.

TABLe 4: Prediction performance of BPNN, RBFNN, and SVM.

\begin{tabular}{lccccccrrr}
\hline Fatigue details & \multicolumn{3}{c}{ BPNN } & \multicolumn{3}{c}{ RBFNN } & \multicolumn{2}{c}{ SVM } \\
MSE & MRE & STD & MSE & MRE & STD & MSE & MRE \\
\hline DC & 2.11 & 2.03 & 0.012 & 19.26 & 6.76 & 0.037 & 36.38 & 8.56 \\
RDI & 0.10 & 1.45 & 0.008 & 1.72 & 5.9 & 0.030 & 2.97 & 7.29 \\
RD & 4.38 & 3.23 & 0.028 & 13.5 & 6.57 & 0.053 & 17.60 & 6.92 \\
DL & 0.16 & 5.81 & 0.054 & 0.18 & 6.65 & 0.031 & 0.27 & 6.86 & 0.037 \\
DC & 0.07 & 5.08 & 0.048 & 0.11 & 5.19 & 0.044 & 0.09 & 4.56 \\
\hline
\end{tabular}

5.3. Ensuring the Weight and the Objective Function. Considering that the impacts on different fatigue details are brought by changing the design parameters, to cover every fatigue detail and optimize the outcomes, we converted the multiobjective problem into a single-objective problem; thus, we need to determine the weight coefficient for each fatigue detail.

For an objective optimizing problem, we assigned each subobjective as a weight representing the importance of the subfunction in multiobjective optimizing problems, and the linear weight of each subobjective can be illustrated as

$$
f(x)=\sum_{i=1}^{n} w_{i} f_{i}(x), i=1,2, \ldots, n .
$$
as

Considering the conditions, formula (4) can be rewritten

$$
\begin{aligned}
w_{i j} & =\frac{\Delta \overline{\sigma_{i j}}}{N_{j}} \times \lambda_{j}, \\
S & =\sum_{i=1}^{2} \sum_{j=1}^{4} w_{i j} \times s_{i j},
\end{aligned}
$$

$s_{i j}$ stands for the expected values of the stress amplitude of the fatigue detail in different engineering conditions, $i$ stands for the corresponding condition, and $j$ stands for the corresponding fatigue detail. $\Delta \overline{\sigma_{i j}}$ is the average stress amplitude of the fatigue detail in different conditions, $N_{j}$ is the 2,000,000 times fatigue level strength of the fatigue detail, where that of DC and RC are 71, that of RDI, RD, and $\mathrm{RC}$ are 80 , according to the Eurocode 3 specifications; $w_{i j}$ is the weight coefficient of the fatigue detail in different conditions. $\lambda_{j}$ is the odd weight coefficient of the fatigue detail, which is inferred from existing statistical data through AHP.

The AHP forms the judging matrix through paired comparisons based on a 9-level scale and implements preference analysis by using matrix theories, finally obtaining the level-weight coefficients [42].

In reference [3], 7000 fatigue damage cases of orthotropic steel decks were analyzed, as shown in Figure 16 and Table 5, and the major types of cracks were obtained.

The fatigue cracks of deck-to-vertical stiffener weld accounted for a high proportion in 7000 fatigue damage cases, which has been cancelled in the current design of the orthotropic steel bridge deck [3]. The importance of each fatigue detail was ensured by the proportion of delicate parts. 


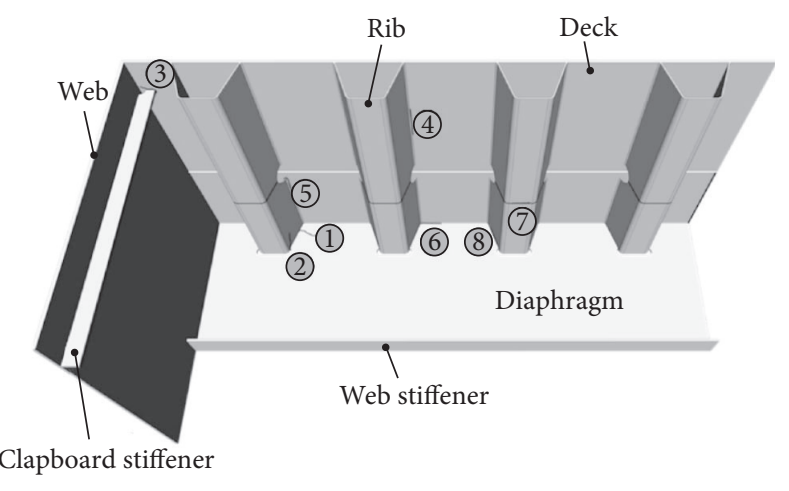

FIgURE 16: Typical fatigue vulnerable locations of OSD.

TABLE 5: Typical fatigue vulnerable location of OSD (unit: \%).

\begin{tabular}{lrc}
\hline Number & Location & Rate \\
\hline (1) & Rib-to-diaphragm weld & 0.9 \\
(2) & Rib-to-diaphragm joints (including cutouts) & 38.2 \\
(3) & Deck-to-vertical stiffener weld & 31.5 \\
(4) & Deck-to-rib weld & 18.9 \\
(5) & Over welded hole joints & 0.6 \\
(6) & Deck-to-diaphragm weld & 2.3 \\
(7) & Rib-to-rib butt weld & 5.7 \\
(8) & Rib-to-side diaphragm joints & 1.7 \\
\hline
\end{tabular}

For DL, it was considered as a deck-to-diaphragm weld. The proportion of each fatigue detail is shown in Table 6 .

According to Table 6, we concluded that the judging matrix only considered the proportion of each detail, which is shown in the following formula:

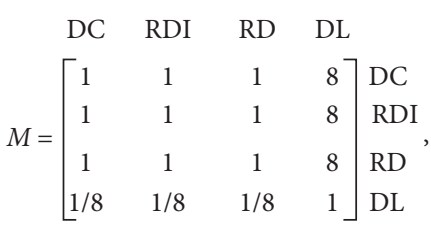

where $m_{i j}=C_{i} / C_{j}, C_{n}$ stands for the importance of the fatigue detail; here, it represents the proportion of each fatigue detail cracks. $m_{i j}$ represents the relative importance between the fatigue details, which are needed to be rounded. To judge whether the created matrix could be accepted, the judging matrix needs to be calculated based on consistency evaluating indicators, as shown in the following formulas:

$$
\begin{aligned}
& C . R=\frac{C . I}{R . I}, \\
& C . I=\frac{\left(\lambda_{\max }-n\right)}{(n-1)} .
\end{aligned}
$$

C.R is the consistent proportion to judge the matrix when C.R $R=0$, and the judging matrix is a perfectly consistent matrix; when $C . R<0.1$, the judging matrix is a satisfying consistent matrix; $\lambda_{\max }$ is the max eigenvalue for the judging matrix; C.I is the indicator to judge the consistency of the matrix; R.I is the indicator to judge the random consistency
TAble 6: Proportion of each fatigue detail crack (unit: \%).

\begin{tabular}{cccccc}
\hline & DC & RDI & RD & DL & Others \\
\hline Rate & 19.1 & 19.1 & 18.9 & 2.3 & 40.6 \\
\hline
\end{tabular}

TABLE 7: Optimization results of parameter calculation (unit: $\mathrm{mm}$ ).

\begin{tabular}{lccccc}
\hline & $h$ & $t_{d}$ & $t_{h}$ & $t_{r}$ & $t_{l}$ \\
\hline Design & 380 & 16 & 12 & 10 & 10 \\
AHP & 376.45 & 17.5 & 13.86 & 8.4 & 8.03 \\
Common & 395.10 & 16.96 & 13.94 & 10.06 & 11.95 \\
\hline
\end{tabular}

of the matrix, which is relevant to the order of the judging matrix and is equal to 0.89 here.

After the calculation, the consistent indicator C.I. $=0$ refers to a perfect consistent matrix. The weights of the odds of occurrence of fatigue crack for DC, RDI, RD, and DL are $0.320,0.320,0.320$, and 0.04 , respectively.

According to the weight calculated through formula (6) under two different engineering conditions and after a series of standardizing processes based on the summation of the factors of each row of the matrix, the values are shown in the following formula:

$$
W=\left[\begin{array}{cccc}
\text { DC } & \text { RDI } & \text { RD } & \text { DL } \\
0.443 & 0.139 & 0.411 & 0.007 \\
0.352 & 0.092 & 0.495 & 0.061
\end{array}\right] \text { condition1 }
$$

The value of the common weight coefficient was based on the literature [31], which is $1 / 4$ of each fatigue detail under every condition.

5.4. Optimized Outcomes. SA is a universal optimizing algorithm that is able to go beyond the partial best solutions and refine the solutions to obtain the overall best solutions [43]. When smaller objective function values were not found after 1000 iteration calculations, the current minimum values were considered as the local optimal solution. In this paper, we adopted two different types of weight coefficients to optimize the stress amplitude in formula (6) through SA and obtained the best construction parameters, as shown in Table 7. The differences of the stress amplitude between the design sizes and the optimized sizes in this paper are shown in Figure 17. $\delta=\Delta \sigma_{o}-\Delta \sigma_{d}$, where $\delta$ stands for the optimized stress amplitude, $\Delta \sigma_{o}$ stands for the stress amplitude of the corresponding optimized sizes, and $\Delta \sigma_{o}$ stands for the stress amplitude of the corresponding design sizes.

To meet the requirements for actual engineering applications, the design parameters should be rounded up in Table 7. After the optimization mentioned above, the optimized outcomes of the two types of weights could both decrease the stress amplitude of each fatigue detail; compared with the common weight, except for RDI under engineering condition 2, AHP optimization results showed a better performance of declining stress amplitude. The optimized design parameter could effectively enhance the fatigue performance of the new orthotropic steel deck. 


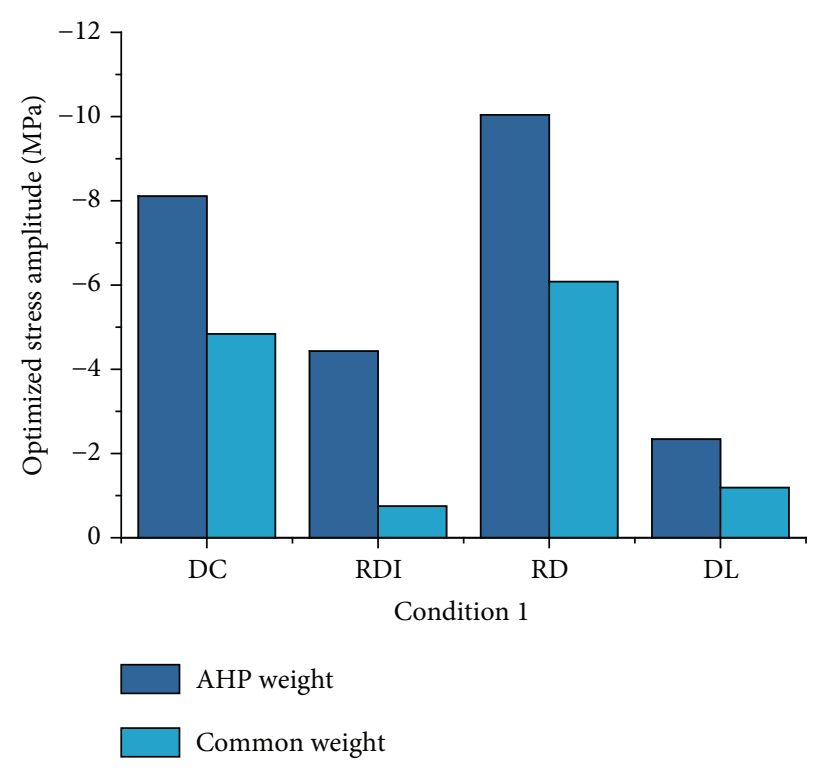

(a)

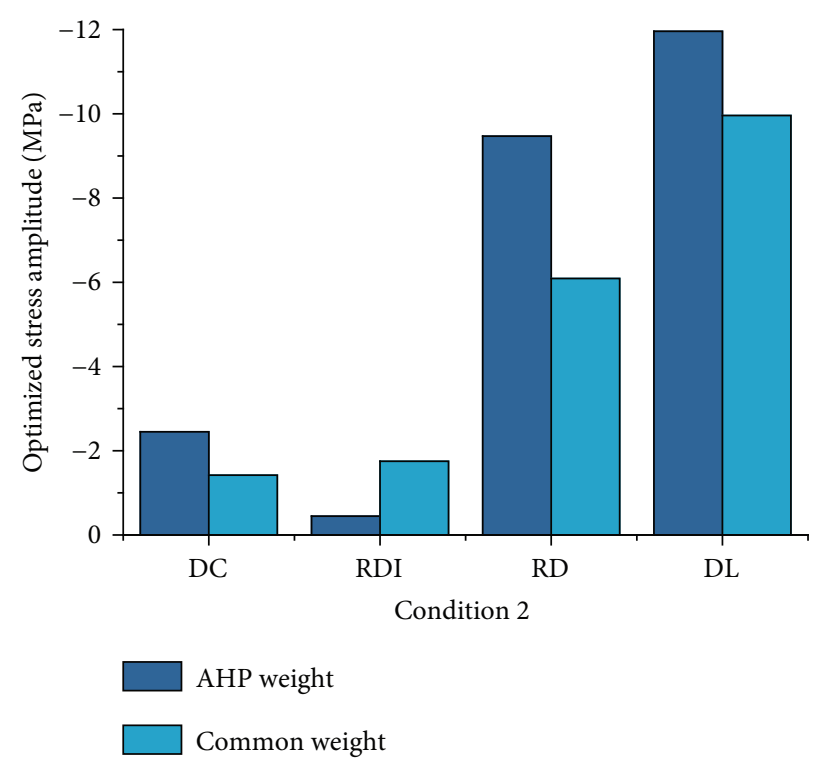

(b)

FIGURE 17: Optimized stress amplitudes of two different weight coefficients.

\section{Conclusion}

The main conclusions can be summarized as follows:

(1) Multiscale analysis models for the new orthotropic steel deck were established, and the calculated stress values of each fatigue detail coincided with the test outcomes, showing the reliability of the FE model.

(2) Considering different types of engineering conditions, the interfere surface for each fatigue detail of the new orthotropic steel deck was established, and the most unfavorable loading position of each fatigue detail was ensured.

(3) The relationship between the design parameters and stress amplitudes was obtained through BPNN, RBFNN, and SVM. Compared with SVM, ANN was more suitable for multiparameter and multiobjective prediction; compared with the two ANN models, BPNN had a better prediction performance and RBFNN had a better efficiency.

(4) A parameter-optimizing method for the new orthotropic steel deck based on BPNN-AHP-SA was proposed. Compared with the optimized outcomes gained by common weight coefficients, the optimized outcomes of the weight coefficients outlined in this essay were more efficient, and the optimized design parameters were able to substantially improve the fatigue performance of the new orthotropic steel deck.

\section{Data Availability}

The data used to support the findings of this study are available from Master Kewei Shi upon request through email (skw1@njtech.edu.cn).

\section{Conflicts of Interest}

The authors declare that they have no conflicts of interest.

\section{Acknowledgments}

This research was funded by the Transportation Science and Technology Project of Jiangsu Province (Grant no. 2019Y18), the National Science Foundation of China (Grant no. 51778288), the Project of Semi-open Longitudinal Rib Orthotropic Steel Bridge Deck Structure and Fatigue Performance Test, and Jiangsu Province Graduate Research Innovation Plan (Grant no. KYCX19_0881).

\section{References}

[1] X. Shao, D. Yi, Z. Huang, H. Zhao, B. Chen, and M. Liu, "Basic performance of the composite deck system composed of orthotropic steel deck and ultrathin RPC layer," Journal of Bridge Engineering, vol. 18, no. 5, pp. 417-428, 2013.

[2] S. Teixeira De Freitas, H. Kolstein, and F. Bijlaard, "Assessment of full-scale retrofitted orthotropic bridge decks," Journal of Bridge Engineering, vol. 22, no. 11, Article ID 04017092, 17 pages, 2017.

[3] Q. H. Zhang, Y. Z. Bu, and Q. Li, "Review on fatigue problems of orthotropic steel bridge deck," China Journal of Highway and Transport, vol. 30, no. 3, pp. 14-30, 2017, in Chinese.

[4] J. Correia, H. Carvalho, G. Lesiuk et al., "Fatigue crack growth modelling of fão bridge puddle iron under variable amplitude loading," International Journal of Fatigue, vol. 9, Article ID 105588, 2020.

[5] G. Lesiuk, B. A. Pedrosa, A. Zięty et al., "Minimal invasive diagnostic capabilities and effectiveness of CFRP-patches repairs in long-term operated metals," Metals, vol. 10, no. 7, Article ID 987, 2020.

[6] B. Pedrosa, J. A. Correia, C. A. Rebelo et al., "Reliability of fatigue strength curves for riveted connections using normal 
and weibull distribution functions," ASCE-ASME Journal of Risk and Uncertainty in Engineering Systems, Part A: Civil Engineering, vol. 6, no. 3, Article ID 04020034, 2020.

[7] Z. Liu, T. Guo, J. Correia et al., "Reliability-based maintenance strategy for gusset plate connections in steel bridges based on life-cost optimization," Journal of Performance of Constructed Facilities, vol. 34, no. 5, Article ID 04020088, 2020.

[8] J. F. Barbosa, J. A. Correia, R. F. Júnior et al., "Fatigue life prediction of metallic materials considering mean stress effects by means of an artificial neural network," International Journal of Fatigue, vol. 135, Article ID 105527, 2020.

[9] J. K. Martinez, P. B. Keating, P. Montenegro et al., "Fracture mechanics analysis of the effect of clamping stress on the fatigue life of riveted built-up railroad girders under variable amplitude loading," Engineering Failure Analysis, vol. 118, Article ID 104812, 2020.

[10] R. G. Wang, Y. Ou, X. L. Xu et al., "Experimental study of fatigue performance of orthotropic steel bridge deck with semi-open longitudinal ribs," Bridge Construction, vol. 48, no. 6, pp. 64-69, 2018, in Chinese.

[11] S. Kainuma, M. Yang, Y.-S. Jeong, S. Inokuchi, A. Kawabata, and D. Uchida, "Experimental investigation for structural parameter effects on fatigue behavior of rib-to-deck welded joints in orthotropic steel decks," Engineering Failure Analysis, vol. 79, no. 11, pp. 520-537, 2017.

[12] Y.-S. Song and Y.-L. Ding, "Influence of local geometric parameters on fatigue performance of orthotropic steel deck," Journal of Central South University, vol. 21, no. 5, pp. 20912099, 2014.

[13] Y. Xia, H. Nassif, E. S. Hwang et al., "Optimization of design details in orthotropic steel decks subjected to static and fatigue loads," Transportation Research Record, vol. 2331, no. 5, pp. 14-23, 2013.

[14] H. X. Huang, M. J. Chajes, D. R. Mertz et al., "Behavior of open steel grid decks for bridges," Journal of Constructional Steel Research, vol. 58, no. 5-8, pp. 819-842, 2002.

[15] W. De Corte, "Parametric study of floorbeam cutouts for orthotropic bridge decks to determine shape factors," Bridge Structures, vol. 5, no. 2-3, pp. 75-85, 2009.

[16] C.-K. Oh, K.-J. Hong, D. Bae, H. Do, and T. Han, “Analytical and experimental studies on optimal details of orthotropic steel decks for long span bridges," International Journal of Steel Structures, vol. 11, no. 2, pp. 227-234, 2011.

[17] M. A. Ahmadi, M. Ebadi, P. S. Marghmaleki, and M. M. Fouladi, "Evolving predictive model to determine condensate-to-gas ratio in retrograded condensate gas reservoirs," Fuel, vol. 124, pp. 241-257, 2014.

[18] M.-A. Ahmadi, B. Pouladi, Y. Javvi, S. Alfkhani, and R. Soleimani, "Connectionist technique estimates $\mathrm{H} 2 \mathrm{~S}$ solubility in ionic liquids through a low parameter approach," The Journal of Supercritical Fluids, vol. 97, pp. 81-87, 2015.

[19] M. Ali Ahmadi and A. Ahmadi, "Applying a sophisticated approach to predict $\mathrm{CO}_{2}$ solubility in brines: application to $\mathrm{CO}_{2}$ sequestration," International Journal of Low-Carbon Technologies, vol. 11, no. 3, pp. 325-332, 2016.

[20] M.-A. Ahmadi, A. Bahadori, and S. R. Shadizadeh, "A rigorous model to predict the amount of dissolved calcium carbonate concentration throughout oil field brines: side effect of pressure and temperature," Fuel, vol. 139, pp. 154-159, 2015.

[21] M.-A. Ahmadi, M. R. Ahmadi, S. M. Hosseini, and M. Ebadi, "Connectionist model predicts the porosity and permeability of petroleum reservoirs by means of petro-physical logs: application of artificial intelligence," Journal of Petroleum Science and Engineering, vol. 123, pp. 183-200, 2014.

[22] A. Baghban, M. A. Ahmadi, B. Hashemi Shahraki et al., "Prediction carbon dioxide solubility in presence of various ionic liquids using computational intelligence approaches," The Journal of Supercritical Fluids, vol. 98, pp. 50-64, 2015.

[23] S. R. Moosavi, D. A. Wood, M. A. Ahmadi, and A. Choubineh, "ANN-based prediction of laboratory-scale performance of CO2-foam flooding for improving oil recovery," Natural Resources Research, vol. 28, no. 4, pp. 1619-1637, 2019.

[24] H. R. Amedi, A. Baghban, and M. A. Ahmadi, "Evolving machine learning models to predict hydrogen sulfide solubility in the presence of various ionic liquids," Journal of Molecular Liquids, vol. 216, pp. 411-422, 2016.

[25] M. A. Ahmadi, M. Ebadi, and A. Yazdanpanah, "Robust intelligent tool for estimating dew point pressure in retrograded condensate gas reservoirs: application of particle swarm optimization," Journal of Petroleum Science and Engineering, vol. 123, pp. 7-19, 2014.

[26] A. Shafiei, M. A. Ahmadi, S. H. Zaheri, A. Baghban, A. Amirfakhrian, and R. Soleimani, "Estimating hydrogen sulfide solubility in ionic liquids using a machine learning approach," The Journal of Supercritical Fluids, vol. 95, pp. 525-534, 2014.

[27] M. A. Ahmadi, R. Haghbakhsh, R. Soleimani et al., "Estimation of $\mathrm{H} 2 \mathrm{~S}$ solubility in ionic liquids using a rigorous method," The Journal of Supercritical Fluids, vol. 92, pp. 62-69, 2014.

[28] M. Bagheri, B. Keshtegar, S. P. Zhu et al., "Fuzzy reliability analysis using genetic optimization algorithm combined with adaptive descent chaos control," ASCE-ASME Journal of Risk and Uncertainty in Engineering Systems, Part A: Civil Engineering, vol. 6, no. 2, Article ID 04020022, 2020.

[29] D. Meng, Z. Hu, P. Wu et al., "Reliability-based optimization for offshore structures using saddle point approximation,", in Proceedings of the Institution of Civil Engineers-Maritime Engineering, pp. 1-10, Telford, UK, August 2020.

[30] H. Xin, A. Mosallam, J. A. F. O. Correia, Y. Liu, J. He, and Y. Sun, "Material-structure integrated design optimization of GFRP bridge deck on steel girder," Structures, vol. 27, pp. 1222-1230, 2020.

[31] M. L. Zhuang and C. Q. Liao, "Analysis on structural parameter optimization of orthotropic steel bridge deck based on fatigue performance," Journal of Southeast University (English Edition), vol. 48, no. 2, pp. 843-850, 2018, In Chinese.

[32] Z. Fu, Y. Wang, B. Ji, and F. Jiang, "Effects of multiaxial fatigue on typical details of orthotropic steel bridge deck," ThinWalled Structures, vol. 135, pp. 137-146, 2019.

[33] M. Li, Y. S. Suzuki, H. C. Wang et al., "Experimental study of asphalt surfacing influence on rib-to-deck joints considering temperature and dynamic effects," Journal of Bridge Engineering, vol. 21, no. 11, Article ID 04016077, 2016.

[34] Y. Wang, Z. Wang, and Y. Q. Zheng, “Analysis of fatigue crack propagation of an orthotropic bridge deck based on the extended finite element method," Advances in Civil Engineering, vol. 2019, Article ID 6319821, 14 pages, 2019.

[35] L. Tian, M. Yang, S. Chang, and J. Qian, "Effects of a new method on stress amplitude and fatigue life of orthotropic steel box girder," Ksce Journal of Civil Engineering, vol. 24, no. 6, pp. 1858-1867, 2020.

[36] X. W. Ye, Y. H. Su, T. Jin et al., "Master S-N curve-based fatigue life assessment of steel bridges using finite element model and field monitoring data," International Journal of Structural Stability and Dynamics, vol. 19, no. 1, Article ID 1940013, 2019. 
[37] B. Cao and Y. Ding, "Influence analysis of plate thickness on welding residual stress of steel deck-rib," Journal of Southeast University (English Edition), vol. 46, no. 3, pp. 565-571, 2016, in Chinese.

[38] K. Shigenobu, Y. S. Jeong, M. Y. Yang et al., "Welding residual stress in roots between deck plate and U-rib in orthotropic steel decks," Measurement, vol. 92, pp. 475-482, 2016.

[39] M. Li, Y. S. Suzuki, K. Hashimoto et al., "Experimental study on fatigue resistance of rib-to-deck joint in orthotropic steel bridge deck," Journal of Bridge Engineering, vol. 23, no. 2, Article ID 04017128, 2018.

[40] J. L. Heng, K. F. Zheng, C. Gou et al., "Fatigue performance of rib-to-deck joints in orthotropic steel decks with thickened edge U-ribs," Journal of Bridge Engineering, vol. 22, no. 9, Article ID 04017059, 2017.

[41] J. B. Ooi, X. Wang, Y. P. Lim et al., "Parametric optimization of the output shaft of a portal axle using finite element analysis," Journal of Mechanical Engineering, vol. 59, no. 10, pp. 613-619, 2012.

[42] A. C. Prakasan, D. Tiwari, Y. U. Shah et al., "Pavement maintenance prioritization of urban roads using analytical hierarchy process," International Journal of Pavement Research and Technology, vol. 38, no. 10, pp. 12869-12879, 2011.

[43] J. V. Martí, F. Gonzalez-Vidosa, V. Yepes, and J. Alcalá, "Design of prestressed concrete precast road bridges with hybrid simulated annealing," Engineering Structures, vol. 48, pp. 342-352, 2013. 